\title{
The Distribution of Colony-forming Cells Among Spleen Colonies
}

L. SIMINOVITCH, E. A. McCULLOCH AND J. E. TILL Department of Medical Biophysics, University of Toronto, and The Ontario Cancer Institute, Toronto, Ontario

\begin{abstract}
Many of the models of hemopoiesis that have been proposed (see, for example, Cronkite et al., '59) are based on the assumption that the continued production of blood cells requires the presence of progenitor cells with the capacity for continued proliferation. From this point of view, hemopoietic tissue may be considered to consist of two compartments; the first, or stem cell compartment, consists of progenitor cells with the capacity to give rise to progeny consisting of both differentiated cells and new stem cells; the second, or differentiated cell compartment, contains cells with limited capacity for cell division, giving rise only to fully differentiated cells. It follows that studies on the processes involved in hemopoiesis require methods for determining the composition of the two compartments. Members of the differentiated cell compartment can frequently be recognized by clear functional markers, for example, the ability to incor- porate radioiron (Alpen and Cranmore, '59). In contrast, recognition and assay of stem cells must involve a procedure in which the descendants of the stem cell are examined. Ideally, such a procedure should test the stem cell not only for its ability to give rise to differentiated descendants (which is the basis for the assay for stem cells described by Gurney and co-workers (Gurney et al., '62)), but should also test for other key properties of stem cells. These include the capacities for self-renewal and extensive proliferation, both of which are required for the maintenance of the stem cell compartment.

Recently, a method has been developed which may fulfill these requirements for studies of stem cells. The method depends on the observation that mouse hemopoietic tissue contains a population of cells that have the capacity to give rise to macroscopic colonies in the spleens of
\end{abstract}

irradiated mice (Till and McCulloch, '61; McCulloch and Till, '62). It has been demonstrated by direct cytological means that these colonies originate from single cells (Becker et al., '63), showing that their cells of origin (colony-forming cells) possess sufficient proliferative capacity to give rise to a macroscopic colony containing of the order of a million cells. Further, histological examination of individual colonies reveals that they contain differentiated cell precursors; indeed, colonies frequently are found to contain more than one kind of differentiated cell, and often erythrocytic, granulocytic and megakaryocytic precursors may be observed within a single colony (McCulloch, '63). Thus the spleen colony technique appears to satisfy some of the requirements of an assay for stem cells, in that the cell type it detects has the capacity for extensive proliferation and is capable of giving rise to progeny containing differentiated cells. However, it remained to be demonstrated that the colony-forming cells possess the capacity for self-renewal. Information bearing on this problem was obtained in the work described here, by testing single colonies for their content of colonyforming cells. The results obtained indicate that colony-forming cells are indeed capable of self-renewal, in that many colonies were found to contain new colony-forming cells. Moreover, the distribution of colony-forming cells per colony was found to be extremely heterogeneous, with some colonies containing many new colony-forming cells and others containing very few. Experiments designed to investigate this heterogeneity have provided 
evidence that it is not an artefact of the methods used to assay for colony-forming cells in colonies, but rather a feature either of colonyforming cells or of the process of colonyformation. The possible significance of this finding will be discussed.

\section{MATERIALS AND METHODS}

Mice. Mice used in these experiments were bred in the animal colonies of the Ontario Cancer Institute. They consisted of $\mathrm{C} \mathrm{H}_{\mathrm{f}} / \mathrm{HaOci}, \mathrm{C} 57 \mathrm{BL} / \mathrm{HaOci}$ and the $\mathrm{F}_{1}$ hybrid between them (main colony) and $\mathrm{C} 3 \mathrm{H} / \mathrm{Hen}$, $\mathrm{C} 57 \mathrm{BL} / 6 \mathrm{~J}$ and the $\mathrm{F}_{1}$ hybrid between them (annex colony). Animals were generally used as irradiated recipients for hemopoietic cell transplants when 8 to 12 weeks of age, and following irradiation, were housed 1-3 animals per cage, and allowed food and water freely.

The assay for colony-forming cells. The assay for colony-forming cells has been described in detail (Till and McCulloch, '61; McCulloch and Till, '62). In brief, an appropriate number of nucleated cells suspended in CMRL 1066 (Parker, '61) is injected intravenously into each of a group of heavily irradiated (900-1,000 rads) recipient mice. After 9-11 days the surviving mice are killed and their spleens fixed in Bouin's solution. Colonies stand out as yellow nodules against the darker background of splenic tissue; these colonies are counted and the average number of colonies per spleen determined. Fixation in Bouin's solution makes the colonies more distinct and facilitates counting. However, the colonies are obvious in unfixed spleens, and may readily be distinguished from supporting splenic tissue (Till and McCulloch, '61).

Irradiation of colony-forming cells in vivo. Since the objective of our experiments was to determine whether or not individual spleen colonies contained colony-forming cells, and how many such cells were present, it was important that the individual colonies used in the experiments be well separated from each other so that they could be dissected out cleanly. This was achieved by preparing animals with spleens containing very few colonies. When this is done by injecting very few nucleated cells into heavily irradiated mice, a high proportion of the animals die during the ten-day period required for the development of colonies. In previous experiments it has been found that survival of animals bearing very few spleen colonies can be increased by injecting a large number of cells, and after two hours reducing by irradiation the number of cells with the capacity to form colonies. The experimental technique has been described (McCulloch and Till, '62). In the present experiments, recipient mice re- ceived 450 rads of $x$-rays, followed by the injection of $7.5 \times 10^{6}$ nucleated bone rnarrow cells. Within two hours a further dose of 550 rads of gamrna rays was delivered. In this way the recipients received 1,000 rads, sufficient to suppress colony-formation by endogenous colony-forming cells (Till and McCulloch, '63), while the grafted cells received 550 rads, a dose following which $0.5 \%$ of the grafted colony-forming cells retain the ability to form colonies (McCulloch and Till, '62). After this procedure, an adequate number of animals survived from 10 to 14 days, and these were found to have spleens with few colonies (1-4) which were usually well separated and easy to dissect individually from the unfixed spleen. In order to control for the possible influence of irradiation of colonyforming cells on the results, unirradiated colonies obtained by injecting a small number of marrow cells into irradiated recipients were also tested for their content of colony-forming cells.

Preparation of cell suspensions. The preparation of cell suspensions from rnarrow, spleen and fetal liver has been described previously (McCulloch and Till, '63). Cell suspensions from single colonies were made as follows: Well-separated colonies were dissected as free as possible from surrounding spleen, and placed in hemagglutination cups each with $0.5 \mathrm{ml}$ of a suspension of heavily (5,000 rads in vitro) irradiated spleen cells in CMRL 1066. The irradiated spleen cells were added as "carrier cells" to diminish possible mechanical losses of the small numbers of cells in the colonies. Five thousand rads is sufficient to render highly improbable the formation of colonies from cells of these spleen suspensions and control groups in which only irradiated spleen cells were injected failed to show 
colonies. The dissected colonies were then chopped finely with scissors, and clumps aspirated up and down in $2 \mathrm{ml}$ disposable plastic syringes. Coarse clumps were ground gently between the bottoms of the hemagglutination cups and the hubs of the plastic syringes. In this way the cells were freed from the supporting spleen stroma.

When required, the total cell content of an individual colony was determined by suspending the colony in a known volume of suspending fluid and determining the cell concentration in this suspension by means of cell counts in a hemocytometer following a 1:10 dilution of the cell suspension in acetic acid with added methylene blue.

Injection of cell suspensions from single colonies. Following dispersion of a single tenday colony the cell suspension was drawn up into the syringe and injected into a heavily irradiated recipient mouse. The cup and syringe were then washed with an additional $0.5 \mathrm{ml}$ of CMRL 1066 which was injected into the same recipient mouse. In this way, a very high proportion of the cells from a colony were injected into the recipient mouse.

For colonies examined after more than ten days of growth, the above procedure was modified in order to avoid confluency of colonies in spleens of recipient animals receiving cells from colonies containing large numbers of CFU. ${ }^{1}$ Instead of injecting the entire $0.5 \mathrm{ml}$ of cells from the dispersed colony into a single recipient mouse, for 11- and 12day colonies, $0.1 \mathrm{ml}$ of the suspension was transferred to a separate cup containing $0.4 \mathrm{ml}$ of CMRL 1066. The contents of this second cup was then injected into one recipient mouse, while the remaining $0.4 \mathrm{ml}$ was injected into another recipient. Both cups were then washed with an additional $0.5 \mathrm{ml}$ of CMRL 1066, which was injected into the same recipients. For 14-day colonies a similar procedure was followed, except that aliquots of 0.45 and 0.05 ml were used.

The method of calculation used for determining the CFU content of single colonies of more than ten days of age was as follows: If both recipient animals survived, and yielded spleens containing discrete colonies, the colony count from the two recipients which had received cells from a given colony were simply summed. If one of the two recipients had died in the ten-day interval between injection and sacrifice, the colony count from the spleen of the remaining animal was multiplied by the appropriate dilution factor. (Where this was done, it is noted in table 3 by superscript 4 ). The same procedure was followed if the spleen of the animal receiving the larger number of cells contained too many colonies to permit a count to be made. Lastly, if the spleen of a single surviving animal contained no colonies, this was scored as a zero only if the animal had received the larger portion of the suspension. If not, the spleen was rejected.

Use of CFU repression to enhance survival of recipient mice. In animals bearing transplants derived from single colonies a proportion of the recipients do not survive the ten days required for colony formation. This results in the loss of a significant amount of information and introduces a possible bias in the data. Many of these deaths can be avoided by the use of the technique of CFU repression described elsewhere (McCulloch and Till, '63). The method depends on the observation that C57BL hemopoietic cells injected into (C3H x $\mathrm{C} 57 \mathrm{BL}) \mathrm{F}_{1}$ hybrids produce very many fewer colonies than when the same number of cells is injected into isologous recipients ("CFU repression"). Although colony-formation is repressed, survival of the recipient animals is enhanced by the presence of the C57BL cells. By choosing appropriate numbers of cells and appropriate combinations of host and donor, animals with a high probability of survival but without spleen colonies can be obtained. Further, it has been shown that the presence of C57BL cells does not appear to interfere with colony-formation by $F_{1}$ hybrid cells (McCulloch and Till, '63). In many of the experiments described in this paper, the colonies tested were of $F_{1}$ hybrid origin, and the irradiated recipients were female $F_{1}$ hybrid mice. Each animal received $10^{6}$ C57BL fetal liver cells intravenously before being used as a recipient for cells from a single colony. In such experiments, as a control, some

\footnotetext{
${ }^{1}$ Colony-forming units, see Results, p. 330.
} 
animals received only irradiated spleen cells, followed by $10^{6}$ C57BL fetal liver cells. In all instances the average number of colonies in the spleens of these controls was less than 0.5 per spleen.

Irradiation procedures. The preparation of recipient animals by irradiation with x-rays, the irradiation of colony-forming cells in vivo and the irradiation of cell suspensions in vitro, have been described in detail elsewhere (McCulloch and Till, '62).

\section{RESULTS}

Measurement of the fraction of injected colonyforming cells which lodge in the spleen

In the spleen-colony assay, only a fraction, f, of the injected colony-forming cells lodge in the spleen and there form colonies, while the remainder of the injected colony-forming cells proliferate elsewhere, for example in marrow, and are not detected by the technique used. The cells which lodge in the spleen and form colonies have been termed colony-forming units (CFU) (Till and McCulloch, '61). In order to calculate the number of colony-forming cells injected from the measured number of CFU, the value of $f$ must be known. A measurement of $f$ may be obtained by injecting animals with marrow containing a known number of CFU, then determining the number of CFU recovered from the spleens of these animals a short time later. The ratio of the number of CFU recovered to the number injected represents $\mathrm{f}$.

The value of $\mathrm{f}$ for marrow cells injected intravenously into irradiated recipients was determined as follows: A group of ten mice was exposed to a dose of $900 \mathrm{r}$ of x-rays, then injected intravenously with a known number of marrow cells. After an interval of two hours, the spleens of these animals were removed, pooled, and dispersed to form a suspension of single cells. A known number of cells from this spleen cell suspension was then injected into a further group of 30 irradiated recipient animals in order to determine its CFU content. A determination of the CFU content of the original marrow suspension was also made. The results of two such experiments are summarized in table 1 . The mean value of $\mathrm{f}$ was found to be 0.17 .

It should be noted that the use of $\mathrm{f}$ as a correction factor provides a minimum estimate of the number of colony-forming cells in a suspension under test because cells lost or damaged in the preparation of the suspension are not taken into account.

Test of single colonies for their content of colonyforming cells. In order to determine the colonyforming cell content of single colonies derived from marrow, individual ten-day spleen colonies were dissected out, dispersed, and re-injected into

TABLE 1

Measurement of the fraction ( $f$ ) of injected marrow colony-forming units (CFU) which may be recovered from the spleen

Exp. 1

Exp. 2

\begin{tabular}{lcc}
\hline & Exp. 1 & Exp. 2 \\
\hline \multicolumn{1}{c}{ Measurernent of the number of CFU given to irradiated recipients } \\
CFU per $10^{5}$ injected cells & $17.4 \pm 1.0$ & $18.9 \pm 1.0$ \\
Number of marrow cells injected & $(2.0 \pm 0.1) \times 10^{7}$ & $(6.0 \pm 0.2) \times 10^{6}$ \\
$\quad$ per recipient mouse & $3480 \pm 270$ & $1130 \pm 65$ \\
CFU injected per recipient mouse & & \\
Mieasurement of CFU recovered from the spleens of the reciplents two hours after injectlon \\
Total cells recovered per spleen & $(1.2 \pm 0.1) \times 10^{\circ}$ & $(1.3 \pm 0.1) \times 10^{8}$ \\
CrU per 105 cells for recovered spleen cells & $0.49 \pm 0.02$ & $0.15 \pm 0.01$ \\
CrU recovered & $590 \pm 55$ & $195 \pm 20$ \\
Fraction of injected CFU recovered (f) & $0.17 \pm 0.021$ & $0.17 \pm 0.021$ \\
\hline
\end{tabular}

1 Estimated standard error. 
irradiated recipient mice (see Materials and Methods). In the same experiment, a number of individual colonies obtained in the same way from the same donor mice were pooled to form a common cell suspension prior to injection into irradiated recipients. The number of cells from this latter suspension injected into each recipient was equal to the average cell content of the colonies used. The results of a typical experiment are given in table 2 . In the table, the results of multiplying the number of CFU per spleen by $1 / \mathrm{f}$ in order to obtain an estimate of the number of colony-forming cells per colony are shown in column 3 .

From table 2, it may be seen that 12 of the 36 individual colonies tested were found to contain a measurable number of colony-forming cells. Thus, by ten days, self renewal of colony-forming cells was detected in at least some of the colonies tested. The remaining 24 colonies showed no CFU when tested. This result indicates only that these colonies did not contain enough colony-forming cells to be detected by the assay. However, as will be seen below (table 3), most colonies tested at later times do contain colony-forming cells, indicating that the colonies showing no CFU at ten days probably do contain colony-formng cells, though few in number $(<6)$.

A noteworthy feature of the data for individual colonies shown in table 2 is the extreme heterogeneity of the distribution of colony-forming cells per colony. That this heterogeneity is not simply due to sampling errors inherent in the spleencolony assay technique is indicated by comparing the data for the individual colonies with that obtained for colonies pooled together prior to injection. For the pooled colonies, one would expect the fluctuations in counts from spleen to spleen to be entirely due to sampling errors, so that the variation among spleens should conform to that predicted by a Poisson distribution, with the variance of the distribution being equal to the mean. The data given in the right half of table 2 are in agreement with this expectation. Thus, it appears that the much greater variation in the single colony data cannot simply be due to sampling errors and must be due to some other cause.

\section{Distribution of colony-forming cells per colony after 10, 12 and 14 days}

It was possible that the heterogeneity of the distribution of colony-forming cells per individual colony arose because the colonies were tested relatively early in their development, and that if the colonies were examined at later times, the distributions would be more homogeneous. For this reason, experiments were carried out in which the distribution of colony-forming cells was determined for colonies after

TABLE 2

Distribution of colony-forming cells per colony for ten-day colonies

\begin{tabular}{|c|c|c|c|c|c|c|}
\hline & \multicolumn{3}{|c|}{ Single colonies } & \multicolumn{3}{|c|}{ Pooled colonies } \\
\hline & $\begin{array}{l}\text { Colony } \\
\text { count per } \\
\text { spleen }\end{array}$ & $\begin{array}{l}\text { Number of } \\
\text { spleens }\end{array}$ & $\begin{array}{c}\text { Estimated } \\
\text { colony- } \\
\text { formers } \\
\text { per colony } 1\end{array}$ & $\begin{array}{l}\text { Colony } \\
\text { connt per } \\
\text { spleen }\end{array}$ & $\begin{array}{c}\text { Number of } \\
\text { spleens }\end{array}$ & $\begin{array}{l}\text { Expected } \\
\text { no. from } \\
\text { Poisson }\end{array}$ \\
\hline & $\begin{array}{r}0 \\
1 \\
2 \\
6 \\
19 \\
21 \\
23 \\
36\end{array}$ & $\begin{array}{r}24 \\
6 \\
1 \\
1 \\
1 \\
1 \\
1 \\
1\end{array}$ & $\begin{array}{r}<6 \\
6 \\
12 \\
35 \\
112 \\
124 \\
135 \\
212\end{array}$ & $\begin{array}{r}0 \\
1 \\
2 \\
3 \\
4 \\
5 \\
>5\end{array}$ & $\begin{array}{l}2 \\
5 \\
2 \\
8 \\
1 \\
1 \\
0\end{array}$ & $\begin{array}{l}2.1 \\
4.6 \\
5.1 \\
3.7 \\
2.0 \\
0.9 \\
0.6\end{array}$ \\
\hline $\begin{array}{l}\text { Total number of colonies: } \\
\text { Total number of spleens: } \\
\text { Mean: } \\
\text { Variance: }\end{array}$ & $\begin{array}{r}113 \\
3.1 \\
66.2\end{array}$ & 36 & & $\begin{array}{l}42 \\
2.2 \\
1.8\end{array}$ & 19 & 19.0 \\
\hline
\end{tabular}

I Obtained from the colony count per spleen by multiplying by $1 / f=1 / 0.17$. 
TABLE 3

Distribution of colony-forming cells per colony for 10, 12- and 14-day colonies

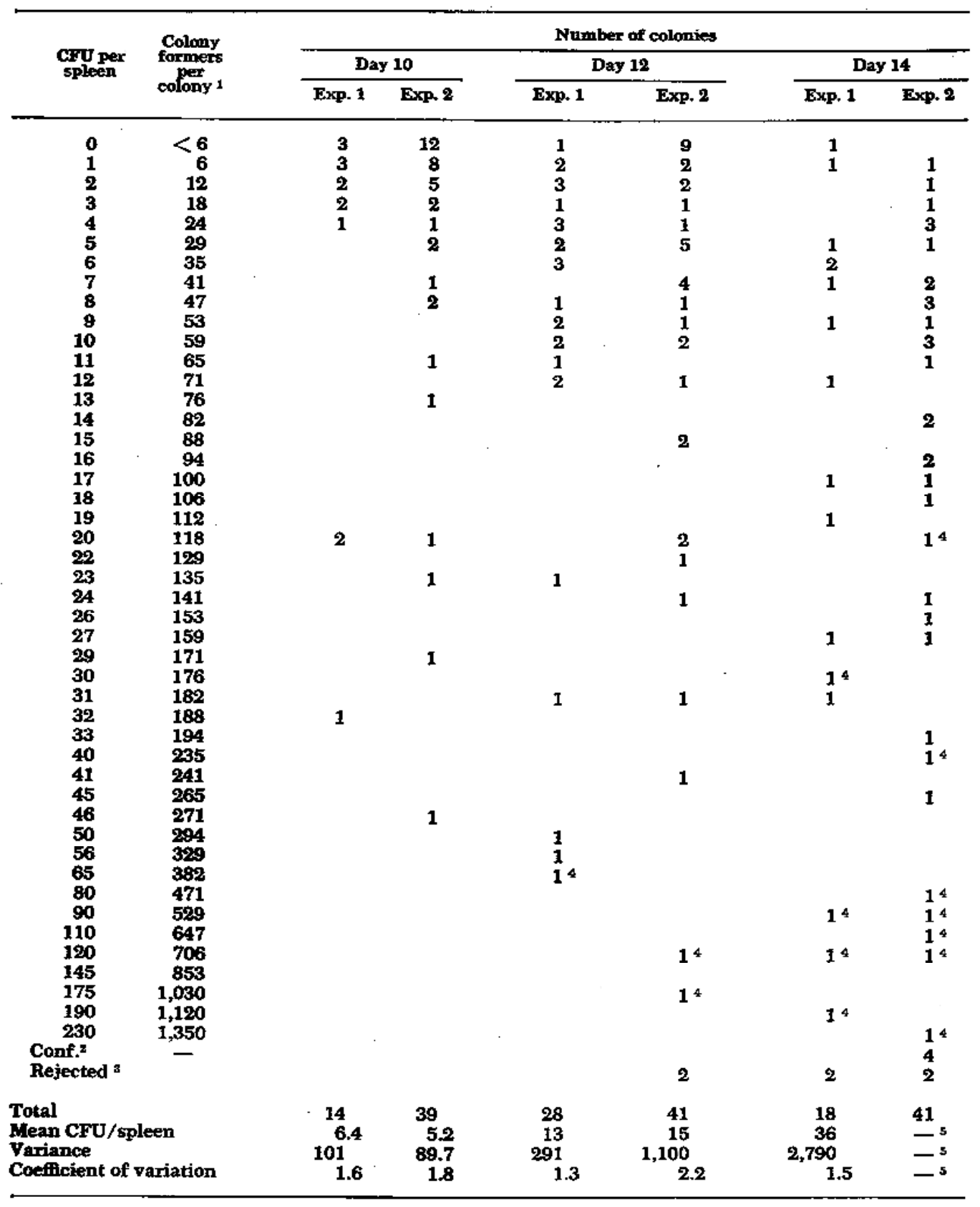

1 Estimated by maltiplying the number of CFU/spleen by 1/0.17.

2 Sigrifies that the speens contained too many colonies to count.

4 Cru per spleen for the indicated colony is an estimate based on the single surviving animal which reseived the smaller fraction of the colony (see "Materials and Methods") 
10,12 and 14 days of growth. The results of two such experiments are presented in table 3. It is immediately apparent from the data that the heterogeneity in the distribution of colony-forming cells per colony is still observed for 12- and 14-day colonies.

Furthermore, as pointed out above, it is apparent from table 3 that for 14-day colonies, relatively few colonies were observed to contain no detectable CFU, and it may be assumed that at times beyond 14 days, essentially all colonies could be found to contain colony-forming cells. Thus, it may be concluded that the majority of colony-forming cells lodging in the spleen are capable of giving rise to new colony-forrning cells. Unfortunately, satellite colonies, presumably derived from colony-forming cells that had migrated from developing colonies and had initiated new colonies at other sites, became apparent in the spleens at times longer than 14 days. This made it impossible to isolate with certainty single primary colonies after more than 14 days of growth.

\section{Distribution of colony-forming cells per colony in colonies derived from unirradiated cells}

The individual colonies used to obtain the data shown in tables 2 and 3 were derived from marrow cells that had been irradiated in vivo with 550 rads of $\mathrm{Co}^{60}$ radiation. This was done in order to obtain a larger percentage survival of colony-bearing mice after 10 to 14 days. However, it was possible that the irradiation of the cells was the cause of the heterogeneity observed in the number of CFU per colony. To test this possibility, an experiment was performed in which colonies derived from unirradiated cells were tested for their content of colony-forming cells. The results obtained for 10- and 11-day colonies are shown in table 4 . It is apparent from the data that colonies derived from unirradiated cells also show a heterogeneous content of colony-forming cells. The coefficients of variation (ratio of the standard deviation to the mean) for the distributions of CFU per colony are similar to those observed for colonies derived from irradiated cells (table 3 ). Thus, the heterogeneity of the distributions shown in
TABLE 4

Distribution of colony-forming cells per colony for 10-and 11-day colonies derived from unirradiated marrow cells

\begin{tabular}{|c|c|c|c|}
\hline \multirow{2}{*}{$\begin{array}{l}\text { CFU per } \\
\text { spleen }\end{array}$} & \multirow{2}{*}{$\begin{array}{l}\text { Colony- } \\
\text { formers } \\
\text { per } \\
\text { colony } 1\end{array}$} & \multicolumn{2}{|c|}{ Number of colonies } \\
\hline & & Day 10 & Day 11 \\
\hline $\begin{array}{c}0 \\
1 \\
2 \\
3 \\
4 \\
5 \\
6 \\
7 \\
9 \\
13 \\
15 \\
19 \\
20 \\
21 \\
25 \\
37 \\
59 \\
70 \\
\text { Rejected }{ }^{2}\end{array}$ & $\begin{array}{r}<6 \\
6 \\
12 \\
18 \\
24 \\
29 \\
35 \\
41 \\
53 \\
76 \\
88 \\
112 \\
118 \\
124 \\
147 \\
218 \\
347 \\
412 \\
-\end{array}$ & $\begin{array}{r}15 \\
9 \\
5 \\
1 \\
1 \\
1 \\
1 \\
1 \\
1\end{array}$ & $\begin{array}{c}12 \\
5 \\
3 \\
2 \\
1 \\
1 \\
1 \\
2\end{array}$ \\
\hline \multicolumn{2}{|c|}{$\begin{array}{l}\text { Total } \\
\text { Mean CFU/spleer } \\
\text { Variance } \\
\text { Coefficient of variation }\end{array}$} & $\begin{array}{r}37 \\
2.8 \\
\mathbf{3 1 . 5} \\
\mathbf{2 . 0}\end{array}$ & $\begin{array}{c}36 \\
8.2 \\
283 \\
2.2\end{array}$ \\
\hline
\end{tabular}

1 Estimated by multiplying the number of CFU/ spleen by $1 / 0.17$.

2 See "Materials and Methods."

3 CFU per spleen is an estimate based on the single surviving animal which received the smallex fraction

tables 2 and 3 was not due to irradiation of the cells from which the colonies were derived.

\section{Size distribution of colonies}

It was possible that the heterogeneity observed in the distribution of colony-forming cells per colony was due entirely to a corresponding heterogeneity in the sizes of the individual colonies tested. To test this point, individual 10- and 12-day colonies were dissected out and each was dispersed in $0.5 \mathrm{ml}$ of medium 1066. Of this $0.5 \mathrm{ml}, 0.2 \mathrm{ml}$ were removed for cell counts and the remaining 0.3 $\mathrm{ml}$ was injected into a recipient mouse for colony counts on the same suspension. The results comparing cell counts and colony counts, for the ten-day colonies are tabulated in table 5. In the table, the colonies are listed in order of size as determined by their total content of cells. It should be pointed out that these cell counts are not 
entirely representative of colony size, in that the cell counts include some cells derived from the heavily irradiated spleen which forms the matrix in which the colonies develop. It is assumed that the number of cells contributed by this source is negligible compared with the number derived from the colony itself.

At the bottom of table 5 the value of the coefficient of variation is given for the distribution of cell counts. Comparison of this value (0.75) with the coefficients of variation for the distribution of CFU per colony for ten-day colonies, given at the bottom of table 3, (1.6 and 1.8) indicates that the variation in cell count is consider-

TABLE 5

Size distribution of single ten-day colonies

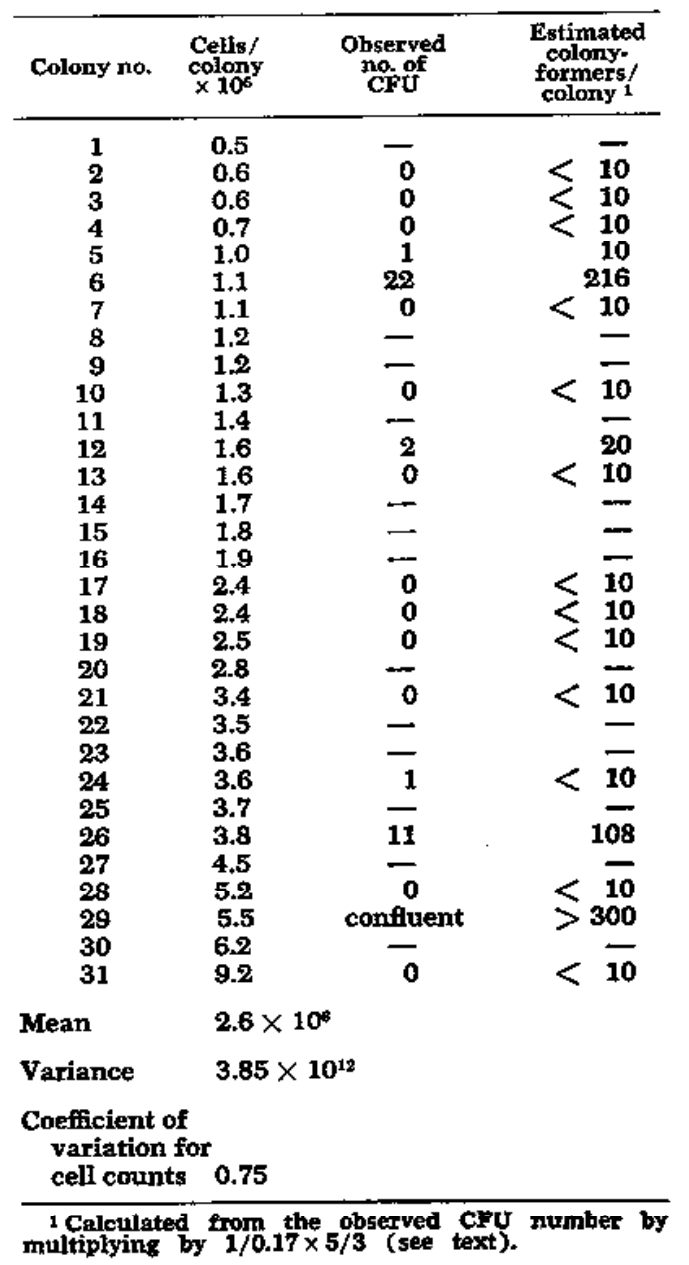

ably less than the variation in CFU per colony, the difference being statistically significant at the $1 \%$ level. This result immediately suggests that the heterogeneity in the number of CFU per colony is not entirely due to variation in colony size.

Also listed in table 5 are the number of CFU observed in the recipient mice which received 0.3 of the $0.5 \mathrm{ml}$ of cell suspension from each colony. Data on CFU content are missing for those cases where the recipient mouse died during the ten-day interval between injection and sacrifice for colony counts. The estimate of the number of colony-forming cells per colony shown in the last column of table 5 was obtained by multiplying the observed colony count by the dilution factor, (5/3) and by $1 / f$. Though the colonies are listed in order of increasing cell content, the colonies containing detectable numbers of CFU are not confined to the largest colonies, which indicates that no clear relationship exists between colony size and CFU content. The data obtained for 12-day colonies support this conclusion.

In these experiments, as in most of the other experiments which formed a part of this study, the individual colonies were classified according to apparent size and color, and an attempt was made to relate the observed CFU content of the colony to its morphological appearance. All such attempts were unsuccessful, and no way has yet been found to predict in advance whether any particular colony will exhibit a large or a small number of CFU per colony.

\section{DISCUSSION}

The experiments reported in this paper were undertaken to determine whether the cells that are recognized by their ability to form colonies of descendants in the spleens of irradiated mice have the capacity for self-renewal. The analysis of spleen colonies has shown that such colonies do indeed contain colony-forming cells. The fact that the number of colonies that contained colony-forming cells increased rapidly between 10 and 14 days, that the large majority of colonies contained colonyforming cells at 14 days, and that the sensitivity of our detection method is of the order of $15-20 \%$, indicates that probably 
all or nearly all colonies contain colonyforming cells. It is clear therefore that the colony-forming cell has the capacity for selfrenewal.

Together with those described earlier, we can now ascribe three properties to the colonyforming cell:

(1) Capacity for extensive proliferation.

(2) Related to the above, but not necessarily the same, the capacity for selfrenewal.

(3) Capacity to give rise to cells with the features of differentiated cells.

On this basis, colony-forming cells may be considered to be a class (though not necessarily the only class) of progenitor cells and the spleen colony method is a quantitative method for their detection.

The second point of interest in our results was the observation that the distribution of numbers of colony-forming cells per colony was extremely heterogeneous, in that a few colonies were found to contain many colonyfonning cells, while the majority contained few. Three possible explanations have been considered for the cause of this heterogeneity.

The first possibility is that the heterogeneous distribution is an artefact of the experimental procedures used. Two lines of evidence indicate that this is not the case. It was demonstrated that the heterogeneity is not due to variation in the ability of different recipient mice to support the development of spleen colonies, since the distribution of colonies among the spleens of the recipients of a suspension of pooled colonies was much less than that observed in animals receiving cells from single colonies (table 2). Also, evidence was obtained which indicated that the observed heterogeneity was not simply due to fluctuations in the number of cells extracted from single colonies, nor was it due only to variations in the size of the individual colonies tested. This was shown by the finding (table 5) that the colonies tested were significantly more homogeneous in respect to their total cell content than in respect to their content of colony-forming units. Further, no gross feature of the colonies, such as colony size or color could be correlated with their content of colony-forming cells. Indeed, no criterion has emerged for the detection of colonies with high or low content of colony-forming cells, except the criterion of test by injection into irradiated recipients.

The second possibility is that the heterogeneous distribution is due to the presence of a mixed population of colony-forming cells, heterogeneous in respect to their ability for selfrenewal, and that these differences are heritable. This possibility might be tested experimentally by determining whether or not individual colony-forming cells give rise to progeny colony-forming cells with an equivalent capacity for self-renewal. For example, the content of CFU in colonies derived from cells of colonies containing many colony-forming cells could be compared with the CFU content of colonies derived from the cells of colonies containing few colony-forming cells. Unfortunately, attempts to carry out this experiment have been complicated by the occurrence of a systematic decrease in the proliferative capacity of colony-forming cells with repeated passage. These observations will be reported in detail in a subsequent publication.

The third possibility is that the heterogeneity develops during the growth of a colony, This possibility must be considered in terms of a model of the processes involved in the formation of a colony. One such model (McCulloch and Till '63) is based on the assumption that colony-forming cells may follow either of two possible pathways. The first, self-renewal, results in the production of new colony-forming cells. The second, differentiation. results in the development of cells adapted to specialized function but with proliferative capacity too limited for colony formation.

From this point of view, the content of a colony after a period of growth in respect to differentiated cells and colony-forming cells may be considered to be the result of a balance between proliferation and differentiation. Indeed, colony formation may be considered as an example of the behavior of a differentiating system in an environment (the heavily irradiated mouse) which provides a strong and relatively constant stimulus. Under these circumstances, it might be expected that the differentiation process, which is often con- 
sidered to be an orderly process, with events succeeding each other in sequence, would result in relatively uniform colonies. However, the observed variation is so large that it appears reasonable to doubt that each colony goes through a very similar series of events in the same order during its development. Nonetheless, if colony formation depends on a balance between proliferation and differentiation, then physiological mechanisms controlling differentiation might be expected to affect this balance. If these mechanisms were such that their control operated at the level of populations of cells rather than at the level of single cells, populations derived from single cells might provide the appearance of lax control, resulting in the beterogeneity observed in colonies. A model of colony formation based on this hypothesis will be described in a subsequent publication.

\section{ACKNOWLEDGMENTS}

The research reported in this paper was supported by the Defence Research Board of Canada (grant no. 9350-14 G\&C), the National Research Council of Canada (AI376), the Medical Research Council of Canada (MA-1420), and the National Cancer Institute of Canada.

The authors are grateful for the helpful participation in this work of Drs. John Fowler and James Kennedy, and for the excellent technical assistance of Miss Rosemary Wyncoll, Mrs. Pat. McRae, Miss
Clair McCausland, and Messers. Richard Course, James Hicks and Robert Kuba.

\section{LITERATURE CITED}

Alpen, E. L., and D. Cranmore 1959 Observations on the regulation of erythropoiesis and cellular dynamics by $\mathrm{Fe}$ 59 autoradiography. In: The Kinetics of Cellular Proliferation, Ed: Stohlman, F. Jr. Grune and Stratton, New York, p. 290-300.

Becker, A. J., E. A. McCulloch and J. E. Till 1963 Cytological demonstration of the clonal nature of spleen colonies derived from transplanted mouse marrow cells. Nature, 197: 452-454.

Cronkite, E. P. T. M. Fliedner, V. P. Bond and J. S. Robertson 1959 Anatomic and physiologic facts and hypotheses about hemopoietic proliferating systems. In: The Kinetics of Cellular Proliferation, Ed: Stohlman, F., Jr., Grune and Stratton, New York, 1959, p. 1-18.

Gurney, C. W., L. G. Lajtha and R. Oliver 1962 A method for investigation of stem-cell kinetics. Brit. J. Haemat., 8: 461-466.

McCulloch, E. A., and J. E. Till 1962 The sensitivity of cells from normal mouse bone marrow to gamrna radiation in vitro and in vivo. Radiation Research, 16: 822-832.

------ 1963 Repression of colony-forming ability of C57BL hematopoietic cells transplanted into non-isologous hosts. J. Cell. and Comp. Physiol., 61: 301-308.

McCulloch, E. A. 1963 Les clones de cellules hematopoietiques in vivo. Rev. Franc Etudes Clin. et Biol., 8: 15-19.

Parker, R. C. 1961 Methods in Tissue Culture, 3rd edition. Paul B. Hoebner Inc., New York.

Till, J. E., and E. A. McCulloch 1961 A direct measurement of the radiation sensitivity of normal mouse bone marrow cells. Radiation Research, 14: 213-222.

1963 Early repair processes in marrow cells irradiated and proliferating in vivo. Radiation Research, 18: 96-105. 